\title{
Two-dimensional spatial distribution modeling of sprinkler irrigation
}

\author{
João Carlos Ferreira Borges Júnior * *D, Camilo de Lelis Teixeira de Andrade ${ }^{2}$
}

$10.1590 / 0034-737 X 202168040002$

\begin{abstract}
Irrigation can provide significant agronomic and financial returns on agricultural activity. The maximization of the benefits obtained from irrigation depends, among other factors, on the water use efficiency, which is intrinsically related to application uniformity. For the sprinkler method, the irrigation uniformity assessment is based on results of labor-intensive field tests in which the two-dimensional water distribution pattern is measured in a grid of catch cans. The aim of this study was to evaluate a simplified methodology for determining the irrigation uniformity using water depth distribution data of a single sprinkler head in operation, positioned at the intersection of two diagonal alignments containing regularly spaced catch cans. Three methods to simulate the spatial water distribution on the alignments were evaluated: linear interpolation (LI), cubic spline (SC) and second-degree polynomial regression (PR). Each of these methods were associated with a procedure to calculate the two-dimensional spatial water distribution. The adequacy of the LI and SC modeling methods was verified by using the Wilcoxon-Mann-Whitney test (p-value $<0.05$ ) applied to the data of the field tests. Mean values of the coefficient of efficiency equals to 0.771 and 0.785 were obtained for the LI and SC methods, respectively. The PR method underperformed the others.
\end{abstract}

Keywords: irrigation efficiency; uniformity coefficient; coefficient of efficiency.

\section{INTRODUCTION}

Irrigation technology can provide significant benefits to crop yield, production quality and financial return. It turns feasible the agricultural activities in periods of high risk of production losses associated to insufficient or irregular rainfall. On the other hand, irrigation imposes the main demand for water resources among the multiple uses of water in Brazil (ANA, 2018), which indicates the importance of seeking high efficiencies.

For the irrigation project designing, it is necessary to define the percentage of adequately irrigated area $(\mathrm{Pa})$, which corresponds to the percentage of the irrigated area that received a water depth equal to or greater than the net irrigation depth $\left(\mathrm{d}_{\mathrm{n}}\right)$ in each irrigation, after discounting the evaporation and wind drift losses. The $d_{n}$ is the net irrigation depth needed to raise the soil water content to the field capacity.

The distribution efficiency associated to a $\mathrm{Pa}$ value $\left(D E_{P_{a}}\right)$ is the ratio between $d_{n}$ and the average irrigation depth received by the soil or crop. The more uniform the water application, the higher the $\mathrm{DE}_{\mathrm{pa}}$, the lower the loss through deep percolation and the smaller the water deficit in the fraction of the irrigated land area that received an irrigation depth lower than $d_{n}$ (Keller \& Bliesner, 2000). Therefore, high irrigation uniformity is an essential factor for obtaining high irrigation efficiency and, consequently, greater crop response to irrigation (Darko et al., 2017; ElWahed et al., 2015; Mantovani et al., 1995). Efforts to improve the irrigation uniformity provide better effects on the crop yield and on the financial return compared to increasing the amount of applied water, especially in regions with water scarcity (Nascimento et al., 2019).

Among sprinkler irrigation methods, classical sprinklers systems (fixed or hand-move lateral systems) are widely used in different regions of Brazil (ANA, 2017). The technical literature addresses different possibilities for carrying out catch-can tests to evaluate the irrigation uniformity of classical methods (Kara et al., 2008; Keller

\footnotetext{
Submitted on September $29^{\text {th }}, 2020$ and accepted on January $19^{\text {th }}, 2021$.

${ }^{1}$ Universidade Federal de São João del-Rei, Departamento de Ciências Agrárias, Sete Lagoas, Minas Gerais, Brazil. jcborges@ufsj.edu.br

2 Embrapa Milho e Sorgo, Sete Lagoas, Minas Gerais, Brazil. camilo.andrade@embrapa.br

*Corresponding author: jcborges@ufsj.edu.br
} 
\& Bliesner, 2000; Salvatierra-Bellido et al., 2018). Tests can be done with one isolated sprinkler head, with one irrigation lateral or with four sprinklers heads (two on each adjacent irrigation lateral) operating concurrently.

When the field test is carried out with a single operating sprinkler head, simulations of overlapping effects can be performed by varying the spacing between the sprinklers heads on the same irrigation lateral (S1), and between the irrigation laterals (S2). In the usual method, catch cans are commonly spaced in the field in $2 \mathrm{~m} \times 2 \mathrm{~m}$ or $3 \mathrm{~m} \times 3 \mathrm{~m}$ mesh, although closest catch cans mesh can be used. The sprinkler head is positioned in the center of the mesh. In this procedure, a high number of catch cans is necessary, which increases as the spacing between catch cans decreases, the test area increases or sprinkler heads with longer jet reach are tested. Therefore, the usual field tests for sprinkler irrigation uniformity is labor and timeconsuming (Zhang et al., 2018), which has motivated the development of alternative methods (Maroufpoor et al., 2019). The arrangement of catch cans in radial lines has been used in tests under indoor conditions performed in laboratories (Fordjour et al., 2020; Issaka et al., 2019; Zhang et al., 2018). Methods that require the use of catch cans arranged only in some alignments of the test area would allow a significant reduction in the number of cans, providing savings in time and financial resources. In addition, this simplified procedure could be adapted to other irrigation methods, such as center pivot and microsprinkler, for estimating the two-dimensional spatial water distribution in a circular area.

The objective of this study was to evaluate a simplified methodology to assess the irrigation uniformity by using water depth data obtained from catch cans placed in two diagonal alignments having a single sprinkler head located in its intersection. Three alternative methods to simulate the two-dimensional water distribution are proposed in this study.

\section{MATERIAL AND METHODS}

The field tests were carried out in an experimental area of Embrapa Milho e Sorgo (Brazilian Agricultural Research Corporation), coordinates $19^{\circ} 27^{\prime} 19.18$ " S; 44 ${ }^{\circ} 10^{\prime} 19.62^{\prime \prime}$ W; altitude 727 m, from January 29 to February 13, 2019. Data on temperature, relative humidity and wind speed were recorded by a Davis Vantage Pro2 - 6152 weather station installed in an area adjacent to the experiment. Twenty-nine tests were carried out using five different models of sprinkler heads:

- ASP1 - Rain Bird 14070H, nozzle 10613114 NOZ, SBN $3 \mathrm{~V}$ (2 tests for each pressure of 300; 350 and $400 \mathrm{kPa}$ ).

- ASP2 - Rain Bird 14070H, nozzle SBN - 3, RNG - 30/40, 10584216 ( 2 tests for each pressure of 300 and $400 \mathrm{kPa}$ and 1 test with the pressure of $350 \mathrm{kPa}$ ).
- ASP3 - Rain Bird, model Pop-Up 7005, nozzle number 8 (2 tests for each pressure of 300, 350 and $400 \mathrm{kPa}$ ).

- ASP4 - Sime, model Ibis mini-gun full circle, nozzles 5 and $6 \mathrm{~mm}$ (2 tests for each pressure of 350, 400 and 450 $\mathrm{kPa})$.

ASP5 - Fabrimar (Plastic) A232, nozzles 4 and 3 mm (2 tests for each pressure of 300,350 and $400 \mathrm{kPa}$ ).

The one-hour duration tests were carried out at different times along the day varying from 8:00 am and $3: 30 \mathrm{pm}$. In each test a unique sprinkler head was installed at the top of $1.5 \mathrm{~m}$ rising tubes. An irrigation evaluation Fabrimar brand kit was used to measure the water distribution of the operating sprinkler head. Catch cans placed at the top of a $0.7 \mathrm{~m}$ aluminum rod were distributed in $3 \mathrm{~m} \times 3 \mathrm{~m}$ mesh. The mesh of 144 catch cans, each located in the center of a cell, occupied a square area with side lengths equal to $36 \mathrm{~m}$ (Figure 1).

Immediately after the one-hour test, the water collected in each catch-can was measured using a graduated cylinder specifically calibrated for the cans. The readings were already in millimeters.

An alternative methodology is proposed to obtain irrigation depths for each cell of the mesh shown in Figure 1, considering a simplified test in which the catch cans are installed only along the four alignments on the two diagonals of the quadrangular area (the two diagonals are represented by the red-dashed lines). In the configuration used in this study, six catch cans spaced $4.24 \mathrm{~m}$ x $4.24 \mathrm{~m}$ were located on each alignment, which can be seen in Figure 1. The first can was located at $2.12 \mathrm{~m}$ from the

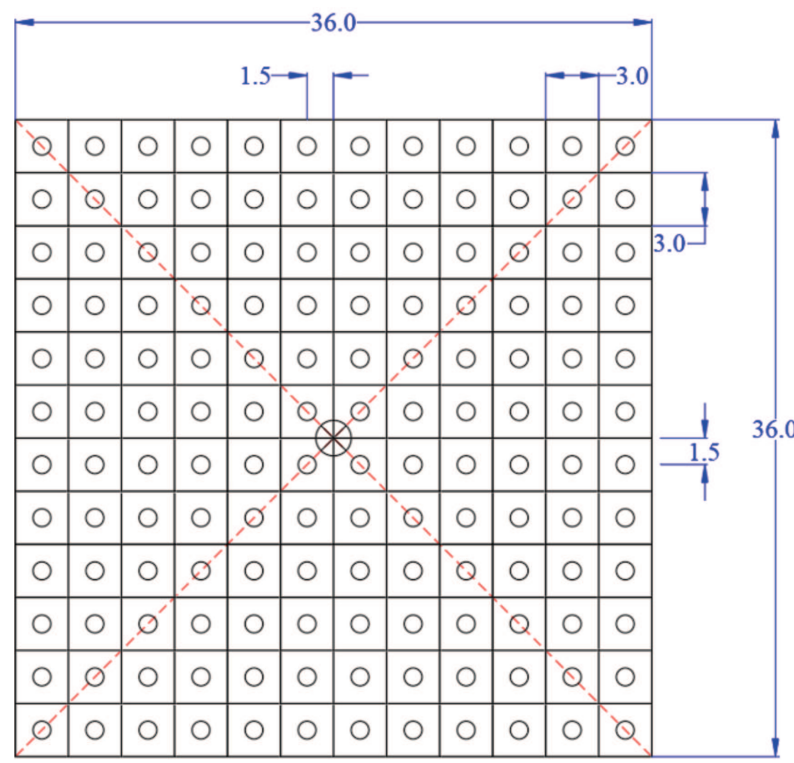

catch-can

$\bigotimes$ sprinkler

catch-cans alignments considered in the alternative methodology

Figure 1: Scheme of the field test arrangement with sprinkler head located at the center of a $3 \mathrm{~m} \mathrm{x} 3 \mathrm{~m}$ catch-can mesh. 
sprinkler head (Figure 1). Thus, the total number of catch cans (24) used in this alternative methodology corresponds to $16.7 \%$ of what would be necessary in the usual full grid methodology.

Polar coordinates of the center of each square cell are required to obtain the irrigation depth values at these points. The irrigation depth in a specific cell located in an area between two adjacent alignments can be estimated by using two values of irrigation depth measured in these two alignments at the corresponding distances. For this estimation, the stronger influence should be exercised by the value measured on the nearest diagonal. Two steps were used to model the distribution of irrigation depths. The first was to get the continuous distribution of irrigation depths along each alignment. Then, a second procedure was applied to calculate irrigation depths at points of the area between the adjacent alignments. Figure 2 shows a scheme in which a cell is located between alignments 2 and 3 , whose center is at a distance D (m) from the center of the area where the sprinkler head is located. The line from the center of the cell to the center of the squared test area defines the angles $\beta_{\mathrm{A}}$ and $\beta_{\mathrm{P}}$, respectively, with the anterior and posterior diagonals (Figure 2).

The estimated irrigation depth for a certain cell $\left(\mathrm{I}_{\mathrm{SC}}\right.$, $\mathrm{mm}$ ) is the weighted mean of the irrigation depths on the alignments at the distance $D$ :

$\mathrm{I}_{\mathrm{SC}}=\frac{\beta_{\mathrm{P}} \mathrm{I}_{\mathrm{DA}}+\beta_{\mathrm{A}} \mathrm{I}_{\mathrm{DP}}}{\beta_{\mathrm{A}}+\beta_{\mathrm{P}}}$

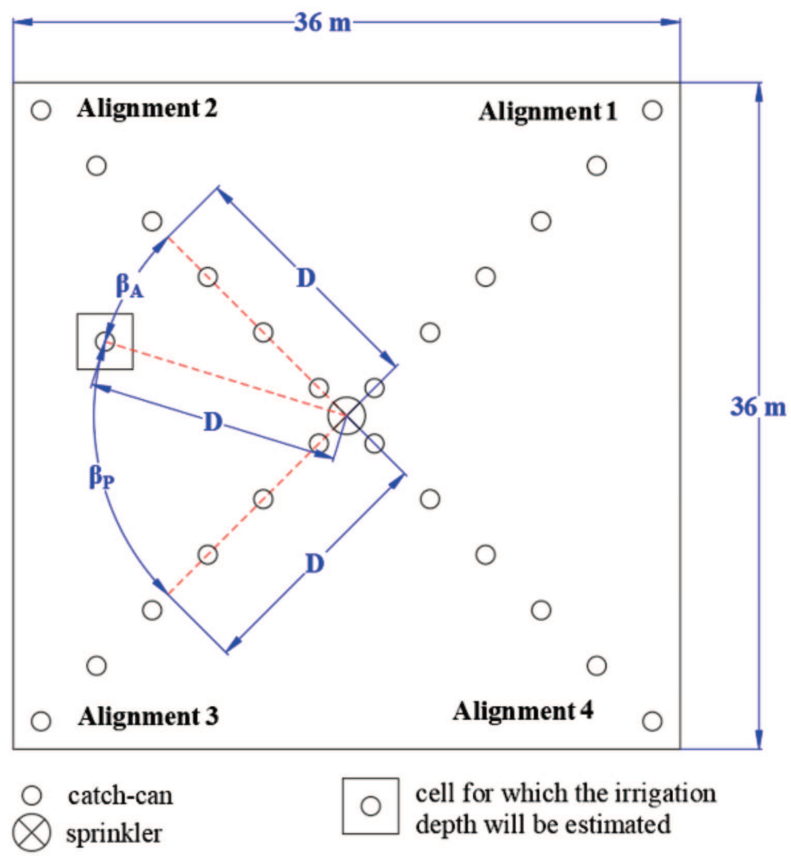

Figure 2: Identification of a cell between alignments 2 and 3 at a distance $\mathrm{D}$ to the center of the area and angles $\hat{a}_{\mathrm{A}}$ and $\hat{\mathrm{a}}_{\mathrm{P}}$ with the adjacent alignments. where $\hat{\mathrm{a}}_{\mathrm{P}}$ and $\hat{\mathrm{a}}_{\mathrm{A}}$ are the angles as indicated in Figure 2; $\mathrm{I}_{\mathrm{DA}}$ $(\mathrm{mm})$ is the irrigation depth $\left(\mathrm{I}_{\mathrm{D}}\right)$ estimated for a position located at the distance $\mathrm{D}$ along the anterior diagonal to the cell (clockwise); and $I_{D P}(\mathrm{~mm})$ is the irrigation depth $\left(I_{D}\right)$ estimated for the position located at distance D along the posterior diagonal to the cell (counterclockwise). The values of $\mathrm{I}_{\mathrm{DA}}$ and $\mathrm{I}_{\mathrm{DP}}$ are obtained by applying one of the equations 2,3 or 4 to estimate irrigation depths along the alignments of catch cans. Three methods to calculate $I_{D}$ were evaluated: linear interpolation (LI), cubic spline (CS) and second-degree polynomial regression (PR). The first two are numerical methods for interpolation and the third for smoothing.

For the LI method, a function was developed to estimate the irrigation depth $\left(\mathrm{I}_{\mathrm{D}}, \mathrm{mm}\right)$ at a point of the alignments located at a distance $\mathrm{D}$ from the center of the area, considering the values measured in the field tests in positions immediately before $\left(\mathrm{x}_{\mathrm{i}}, \mathrm{m}\right)$ and $\operatorname{after}\left(\mathrm{x}_{\mathrm{i}+1}, \mathrm{~m}\right)$. The following equation was used:

$\mathrm{I}_{\mathrm{D}}=\mathrm{I}_{\mathrm{Di}}+\left(\mathrm{I}_{\mathrm{Di}+1}-\mathrm{I}_{\mathrm{Di}}\right) \frac{\mathrm{D}-\mathrm{X}_{\mathrm{i}}}{\mathrm{X}_{\mathrm{i}+1}-\mathrm{X}_{\mathrm{i}}}$

where $I_{D i}(m m)$ and $I_{D i+1}(\mathrm{~mm})$ are the irrigation depths observed in the catch cans at distance $x_{i}(m)$ and $x_{i+1}(m)$, respectively $\left(\mathrm{x}_{\mathrm{i}}<\mathrm{D}<\mathrm{x}_{\mathrm{i}+1}\right)$. The ' $\mathrm{i}$ ' index indicates the position of the six catch cans in the alignments on diagonals, ranging from 0 to 5 .

Similarly, a function was developed for the CS interpolation method (Equation 3). The second derivative was set to zero (natural spline) at the initial and final position (Gerald \& Wheatley, 2004), that is, for the closest catch-can ( $\mathrm{i}=0)$ and the most distant catch-can $(\mathrm{i}=5)$ to the sprinkler head on each diagonal alignment. The irrigation depth $\left(\mathrm{I}_{\mathrm{D}}\right)$ was then calculated:

$I_{D}=a_{i}\left(D-x_{i}\right)^{3}+b_{i}\left(D-x_{i}\right)^{2}+c_{i}\left(D-x_{i}\right)+d_{i}$

where $a_{i}, b_{i}, c_{i}$ and $d_{i}$ are specific coefficients for each interval $\left[\mathrm{x}_{\mathrm{i}}, \mathrm{x}_{\mathrm{i}+1}\right]$. In addition to Equation 3, macros for obtaining the coefficients $a_{i}, b_{i}, c_{i}$ and $d_{i}$ were developed based on the procedures described in Gerald \& Wheatley (2004).

The PR method was based on the equation:

$\mathrm{L}_{\mathrm{D}}=\mathrm{A}_{2} \mathrm{D}^{2}+\mathrm{A}_{1} \mathrm{D}+\mathrm{A}_{0}$

where the $\mathrm{A}_{2}, \mathrm{~A}_{1}$ and $\mathrm{A}_{0}$ are coefficients of a second-degree polynomial adjusted to the irrigation depths measured along the diagonal alignment. The coefficients were obtained using numerical analysis procedures (Gerald \& Wheatley, 2004) for second-degree polynomial regression.

The resulting curvature of the functions could generate inconsistent negative irrigation depths when applying the CS and PR methods, especially for positions in the diagonal far from the sprinkler head. Thus, a condition to convert estimated negative irrigation depths to zero was added for these two methods. 
Three statistics were applied to assess the model performance: 1 - The error in relation to the observed test mean (EM, \%, Equation 5); 2 - the mean absolute error (MAE, mm, Equation 6) and; 3 - the modified coefficient of efficiency $\left(\mathrm{E}_{1}\right.$, dimensionless, Equation 7). These three statistics were applied in the goodness of fit analysis for each field test and each modeling method (LI, CS and PR). The coefficient $\mathrm{E}_{1}$ (Legates \& McCabe, 1999) was chosen in this study because it is less sensitive to extreme values (outliers), compared to the Nash and Sutcliffe's coefficient of efficiency (Legates \& McCabe, 2013; Willmott et al., 2012; Willmott et al., 2015). The equations are:

$\mathrm{EM}=100 \frac{\mathrm{I}_{\mathrm{ma}}-\mathrm{I}_{\mathrm{m}}}{\mathrm{I}_{\mathrm{m}}}$

$\mathrm{MAE}=\frac{\sum_{\mathrm{j}=1}^{\mathrm{N}}\left|\mathrm{Ia}_{\mathrm{j}}-\mathrm{I}_{\mathrm{j}}\right|}{\mathrm{N}}$

$E_{1}=1-\frac{\sum_{j=1}^{N}\left|I_{j}-I_{j}\right|}{\sum_{j=1}^{N}\left|I_{j}-I m\right|}$

where Ima ( $\mathrm{mm})$ is the mean irrigation depth estimated in each test, resulting from the application of one of the three methods; Im ( $\mathrm{mm})$ is the mean irrigation depth measured in each field test; Ia ( $\mathrm{mm}$ ) is the irrigation depth estimated at each cell by applying one of the methods; I $(\mathrm{mm})$ is the irrigation depth measured in each cell; and $\mathrm{N}$ (120) is the number of cells of the test area subtracted by the number of cells in the four diagonal alignment (Figure 1). The irrigation depths of the cells located at the diagonals were recorded in the field tests. Therefore, these values do not vary according to the method, which justifies their exclusion of the analyzes. Thus, Ima and Im are the means of 120 values verified in each test.

The Wilcoxon-Mann-Whitney test (Mann \& Whitney, 1947; Wilcoxon, 1945; Yue \& Wang, 2002) was also applied for each field test at $5 \%$ significance level, under the null hypothesis that the observed and modelled irrigation depths have same distribution. This non-parametric test was chosen due to the non-normality of the irrigation depths data distribution in each test, previously verified by the Lilliefors test at $5 \%$ significance level.

The differences between the Christiansen's uniformity coefficient (CUC, \%) obtained with irrigation depths observed in the field tests and the CUC determined using irrigation depths estimated by one of the proposed methods were also compared. Simulations of CUC values were performed considering four sprinkler heads spaced $18 \mathrm{~m} \mathrm{x}$ $18 \mathrm{~m}$, by applying the equation 8 (El-Wahed et al., 2015; Maroufpoor et al., 2019):

$\mathrm{CUC}=100\left(1-\frac{\sum_{\mathrm{j}=1}^{\mathrm{Nt}}\left|\mathrm{Y}_{\mathrm{j}}-\mathrm{Ym}\right|}{\mathrm{Nt} Y \mathrm{Ym}}\right)$

where $\mathrm{Y}_{\mathrm{j}}$ is equivalent to Ij or Iaj and $\mathrm{Ym}$ is equal to Im or Ima, depending on whether observed or estimated values were used in the calculations, respectively. $\mathrm{Nt}$ is equal to 144 , considering all the cells in the area between four sprinkler heads.

Linear regression was also applied to directly compare the datasets of observed and estimated irrigation depths. In addition, the spatial distribution of absolute errors $(A E=|I a-I|)$ and the distribution of the relative errors to the means (RE, \%) of each test were also studied. $\mathrm{RE}$ was added to the set of performance statistics due to the indication of proportionality in relation to the observed mean of each field test. The occurrence of null irrigation depths prevents the calculation of errors in relation to the values observed in each cell. The RE was calculated by applying the equation:

$\mathrm{RE}=100 \frac{\mathrm{I}_{\mathrm{a}}-\mathrm{I}}{\mathrm{Im}}$

The total data set from the 29 field tests was used to obtain the AE and RE distributions and to perform the linear regression. The DecisionTools Suite version 7.5 software (Palisade Corporation, 2016) was applied to study the probability distributions of the statistics. The software $\mathrm{R}$ (R Core Team, 2019) version 4.0.2 was used to process the Wilcoxon-Mann-Whitney test, to plot surface charts for the spatial distribution of $\mathrm{AE}$ and to build the boxplots of EM, MAE, E, CUC differences and RE. Boxplots will have the standard presentation, showing the median value (solid horizontal line inside the box), mean value (black dots inside the box), the 25th (the lower end of the box) and 75th (the upper end of the box) percentile values, and the open dots indicate outliers. The upper whisker in boxplots shows the lowest value between the maximum value of the studied variable or the value of $\mathrm{Q}_{3}+1.5(\mathrm{IQR})$, where $\mathrm{Q}_{3}$ is the value of the studied variable at the 25 th percentile and IQR is the interquartile range. The lower whisker in boxplots shows the highest value between the minimum value of the studied variable or the value of $\mathrm{Q}_{1}-1.5(\mathrm{IQR})$, where $\mathrm{Q}_{1}$ is the value of the studied variable at the 25 th percentile. The computational procedures for applying the methods were implemented in Microsoft Excel spreadsheets including the use of macros written in Visual Basic.

\section{RESULTS AND DISCUSSION}

\section{Analysis of results grouped by tests}

The averages of wind speed, temperature and relative humidity were $1.6 \mathrm{~m} \mathrm{~s}^{-1}, 28.6^{\circ} \mathrm{C}$ and $55.6 \%$, respectively, in the field tests. The coefficients of variation were $35 \%$, $11 \%$ and $25 \%$, respectively, for wind speed, temperature, and relative humidity. The mean irrigation depths recorded in each one of the 29 tests carried out with only one sprinkler head varied from 1.6 to $2.7 \mathrm{~mm}$. Considering the whole dataset, the mean and median of the irrigation depth were $2.1 \mathrm{~mm}$ and the coefficient of variation was $16.4 \%$. 
Boxplots for the EM, MAE, $\mathrm{E}_{1}$, and p-values of the Wilcoxon-Mann-Whitney test are presented in Figure 3. These results indicate a slightly better performance of CS method compared to LI. The PR method performed worse than the other two.

The mean irrigation depth at the canopy level (Im), after subtracting the losses due to evaporation and wind drift, is a fundamental factor for the irrigation assessment and to define the irrigation time. This highlights the importance of EM statistic to assesses the performance of the methods. Mean EM of 3.4\%, 1.0\% and $4.9 \%$ were obtained for the LI, CS and PR methods, respectively; the medians of EM were $3.3 \%, 0.1 \%$ and $4.9 \%$, respectively, for the LI, CS and PR methods (Figure 3A). The maximum $(13.4 \%)$ and minimum $(-11.4 \%)$ EM were obtained for the PR method. The smallest amplitude of EM was found for the CS method. The EM equivalent to the 90th percentile was $10.9 \%, 6.6 \%$ and $13.0 \%$, respectively, for the LI, CS
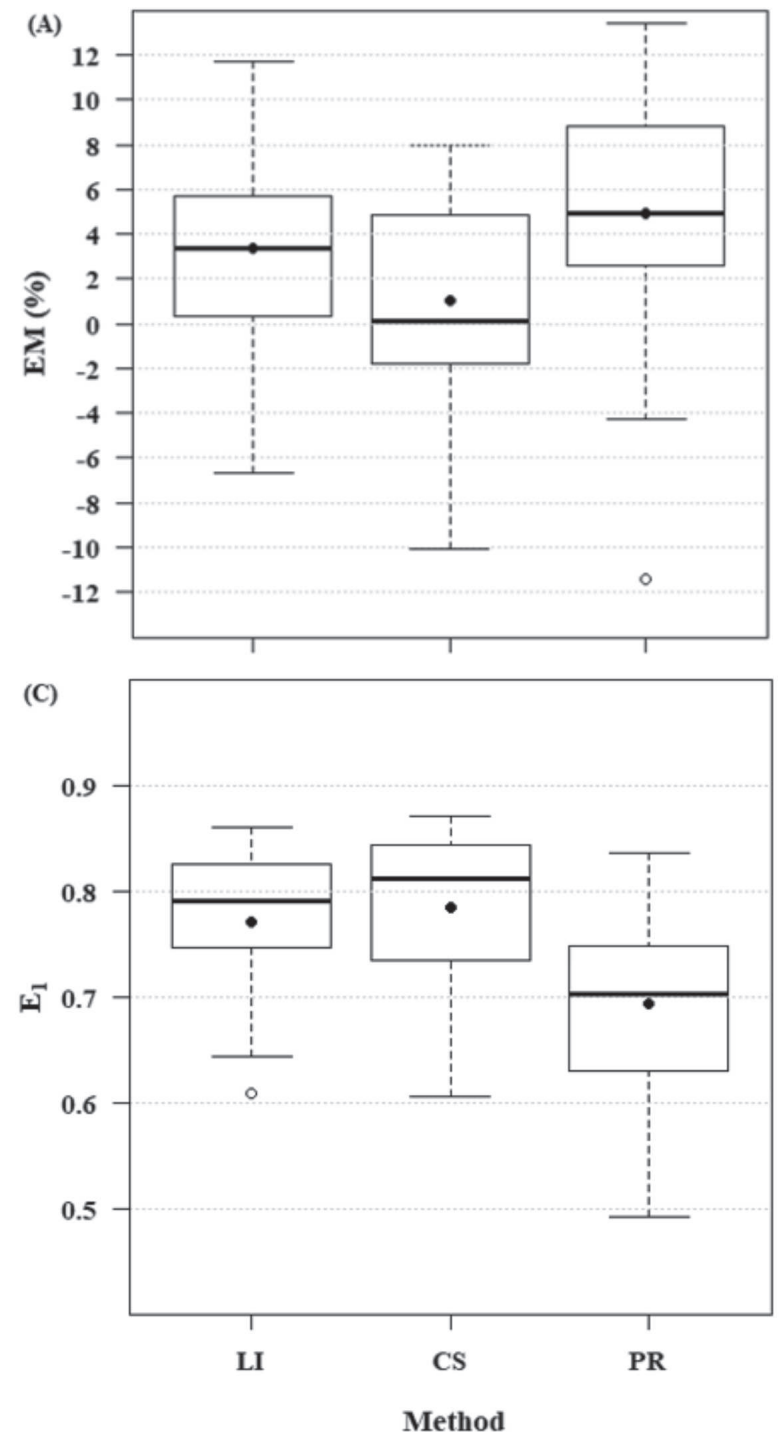

and PR. For the 10th percentile, EM of $-2.4 \%,-4.7 \%$ and $2.6 \%$ were obtained for the LI, CS and PR methods, respectively.

Similar distributions of MAE for the 29 tests were verified for the LI and CS methods, that outperformed the PR method (Figure 3B). The means of MAE, which is slightly higher than the medians, were $0.40,0.37$ and $0.53 \mathrm{~mm}$, for the LI, CS and PR methods, respectively. Two upper outliers were observed for the ASP3 configuration operating at pressure of $400 \mathrm{kPa}$ irrespective of the three methods used. These outliers are due to the significant distortion in the water distribution pattern and variation of the irrigation depths collected in the four alignments. For the PR method, a third higher outlier was obtained for the test of the ASP2 configuration at $400 \mathrm{kPa}$ pressure. Values of $0.52,0.51$ and $0.87 \mathrm{~mm}$ were obtained, respectively, for the LI, CS and PR methods at the 90th percentile of the empirical probability distributions of MAE.
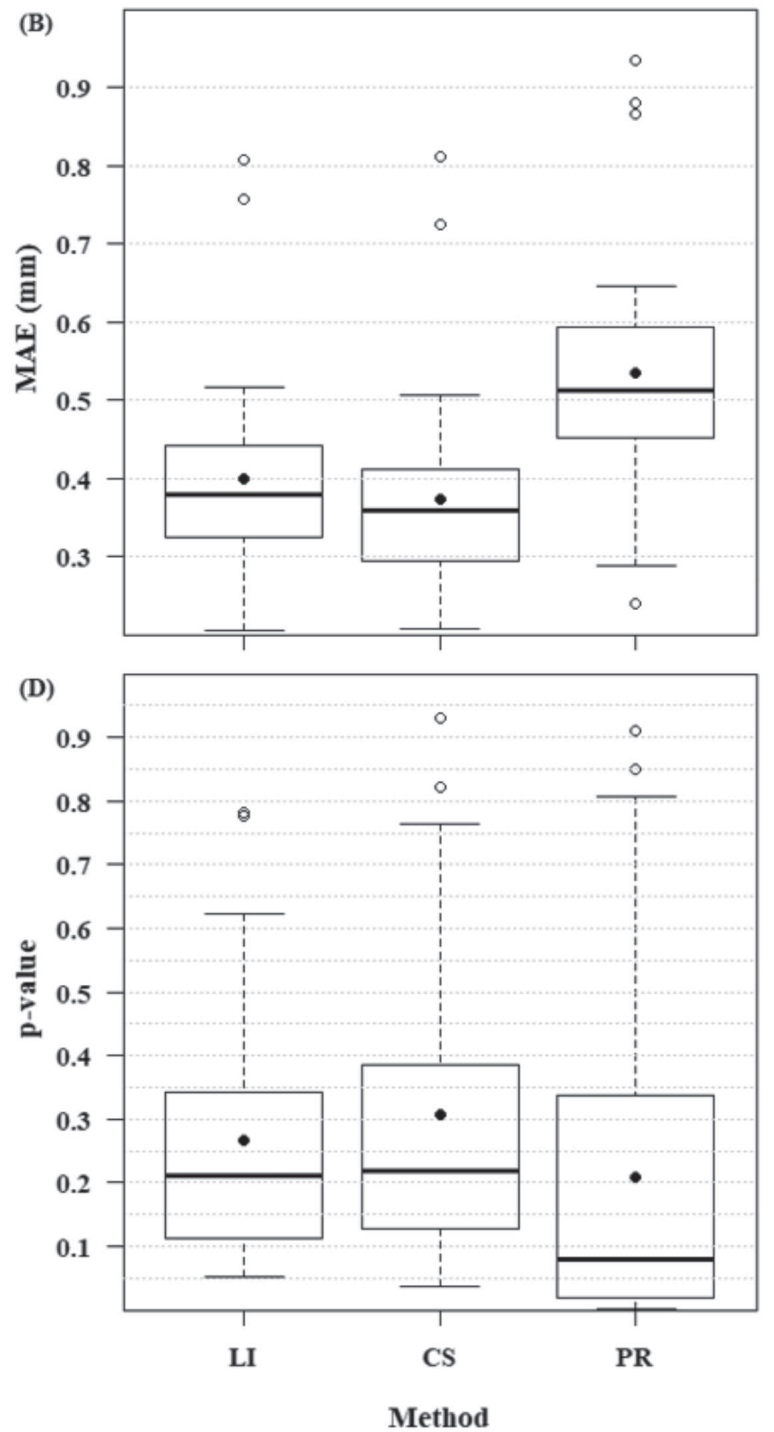

Figure 3: Boxplots with means (black dots) of EM, MAE, $E_{1}$, and p-value by the Wilcoxon-Mann-Whitney test, for the methods linear interpolation (LI), cubic spline (CS) and second-degree polynomial regression (PR). 
The means of $\mathrm{E}_{1}$, lower than the medians, were 0.771 ; 0.785 and 0.694 for LI, CS and PR methods, respectively (Figure 3C). A value of 0.785 for $\mathrm{E}_{1}$ indicates that the model could explain $78.5 \%$ of the absolute difference between observed and predicted values (Legates \& McCabe, 2013), a direct interpretation from Equation 7 and applicable to positive values of this index (Willmott et al., 2015). For 26 of the 29 trials, the highest $\mathrm{E}_{1}$ values were verified for the CS method. In four tests, the highest values of $\mathrm{E}_{1}$ were verified for the LI method (one tie). The lowest $\mathrm{E}_{1}$ values were obtained with the PR method in 28 tests and for one test the lowest $E_{1}$ value was determined for the LI method. The 10th percentile of the $E_{1}$ values distribution were $0.644,0.651$ and 0.546 for the LI, CS and PR methods, respectively.

No p-value lower than 0.05 was obtained by applying the Wilcoxon-Mann-Whitney test for the LI method (Figure 3D). A minimum value of 0.0506 was determined, which indicated the equivalence between the distributions of observed and modeled values, at a 5\% significance level. For the CS method, p-values slightly less than 0.05 were obtained for two tests: one for ASP1 configuration (pvalue $=0.0463$ ) at a pressure of $350 \mathrm{kPa}$ and another for ASP2 configuration ( $p$-value $=0.0358$ ) at a pressure of $300 \mathrm{kPa}$. For the PR method, p-values ranging from 0.0023 to 0.0434 were obtained in 12 out of the 29 tests. P-values equal to $0.0678 ; 0.0542$ and 0.0093 were obtained for the 10th percentile, respectively, for LI, CS and PR methods.
In the simulations of the distribution of irrigation depths considering four sprinkler heads spaced $18 \mathrm{~m} \times 18$ $\mathrm{m}$, the CUC values for observed data ranged from $71.3 \%$ to $90.8 \%$, with an average of $84.7 \%$. CUC values smaller than $80 \%$ were verified for two tests of the ASP3 configuration, operating at $400 \mathrm{kPa}$. Figure 4 presents boxplots for the differences, in percentage points, between CUC estimated with the three methods, and the CUC based on the measured data.

The averages obtained for the differences in CUC were $3.7 ; 2.9$ and 4.8 percentage points, respectively, for LI, CS and PR methods (Figure 4). For the 10th percentile, the differences in CUC were $-0.3 ;-1.4$ and 1.3 percentage points, respectively, for LI, CS and PR methods. In the 90th percentile, the differences were 7.8; 7.0 and 11.2 percentage points for LI, CS and PR methods, respectively. These data also indicate a similar performance of the LI and CS methods and their superiority in relation to the PR method. Again, the outliers in Figure 4 for the three methods occurred for the ASP3 configuration operating at $400 \mathrm{kPa}$ pressure, in which atypical distributions along two diagonals were recorded in the field tests. The boxplots show a tendency of better CUC values determined with estimated irrigation depths as compared to CUC values obtained from observed data. This behavior was expected since that any discrepancies obtained in catch cans located outside of the diagonals (Figure 1) are not captured when

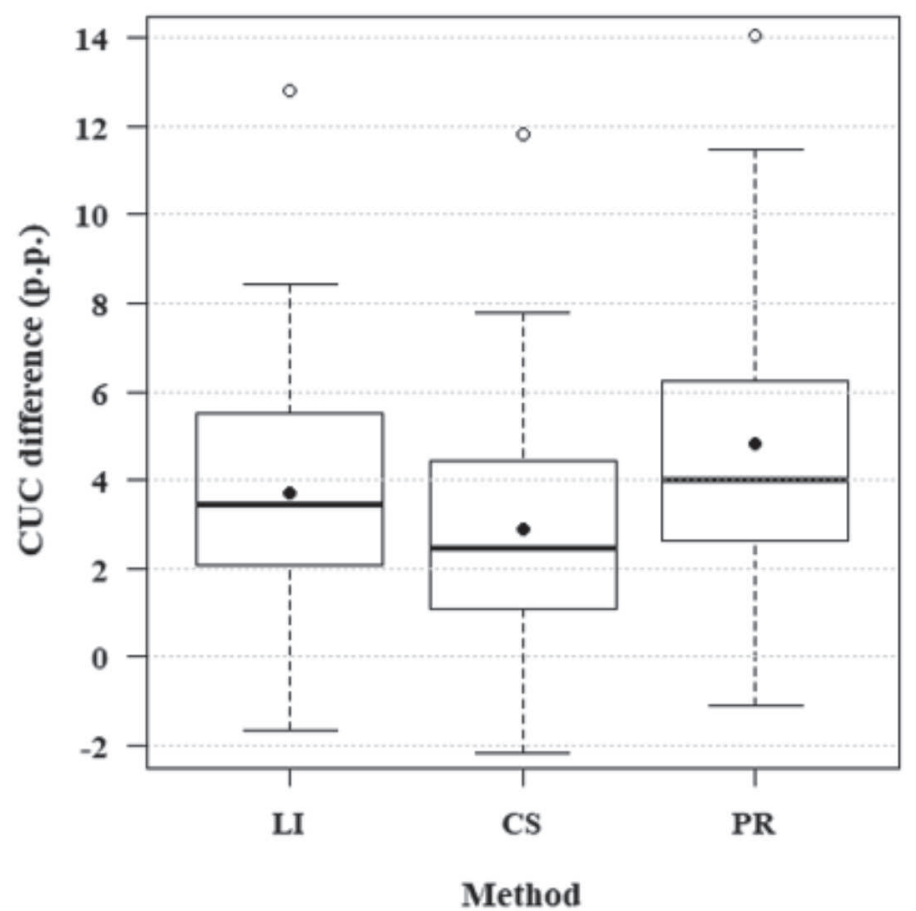

Figure 4: Difference expressed in percentage points for CUC values obtained from the modeled and observed irrigation depths, for a simulated sprinkler head spacing of $18 \mathrm{~m} \mathrm{x} 18 \mathrm{~m}$ and for the methods linear interpolation (LI), cubic spline (CS) and second-degree polynomial regression (PR).

Rev. Ceres, Viçosa, v. 68, n.4, p. 257-266, jul/aug, 2021 
estimates are made using the modeling methods. However, variations in the distribution of irrigation water, collected at the canopy level, tend to be mitigated by the soil-water redistribution process. This effect promote better uniformity of the water content in the soil as compared to that of collected irrigation depths (AlKufaishi et al., 2009; Rezende et al., 1998; Simionesei et al., 2016). The crop canopy is another factor that can contribute to improving the uniformity of irrigation distribution (Zapata et al., 2018).

\section{General data set analysis}

Scatterplots were generated using observed and modeled irrigation depths for 3480 data points (120 data points for each of the 29 field tests; Figure 5). The coefficients of determination obtained from the regression indicate a better performance of the LI and CS methods $\left(\mathrm{R}^{2}=0.93\right)$ compared to the PR method $\left(\mathrm{R}^{2}=0.89\right)$. The CS method provided the regression coefficient closest to one and the constant closest to zero, with the regressed line almost overlapping the 1:1 line, indicating it performed better than the LI method.
The spatial distributions of the mean of the absolute error (AE) calculated for each grid cell of the 29 field tests are shown in Figure 6. As expected, the highest AE values were observed in grid cells close to the sprinkler head, where the largest irrigation depths were applied. The highest $\mathrm{AE}$ values were determined when using the PR method (maximum AE of $1.35 \mathrm{~mm}$ ) and the lowest for the CS method (maximum AE of $0.98 \mathrm{~mm}$ ). The highest AE for one grid cell was $1.08 \mathrm{~mm}$ when using the LI method.

The characterization of the RE distributions obtained with the application of the methods LI, CS and PR is shown in Figure 7 and Table 1. Corroborating the previous analyzes, the CS and LI methods outperformed the PR method. The CS method provided a mean closest to zero, the lowest interquartile interval and the lowest standard deviation, which indicates the best performance. However, the highest amplitude between maximum and minimum values was obtained for this method. Despite the short interquartile intervals, there is considerable variation in the RE and the occurrence of extreme values, which is reflected in the leptokurtic pattern (kurtosis > 3 ) of the distributions. The mode for the three
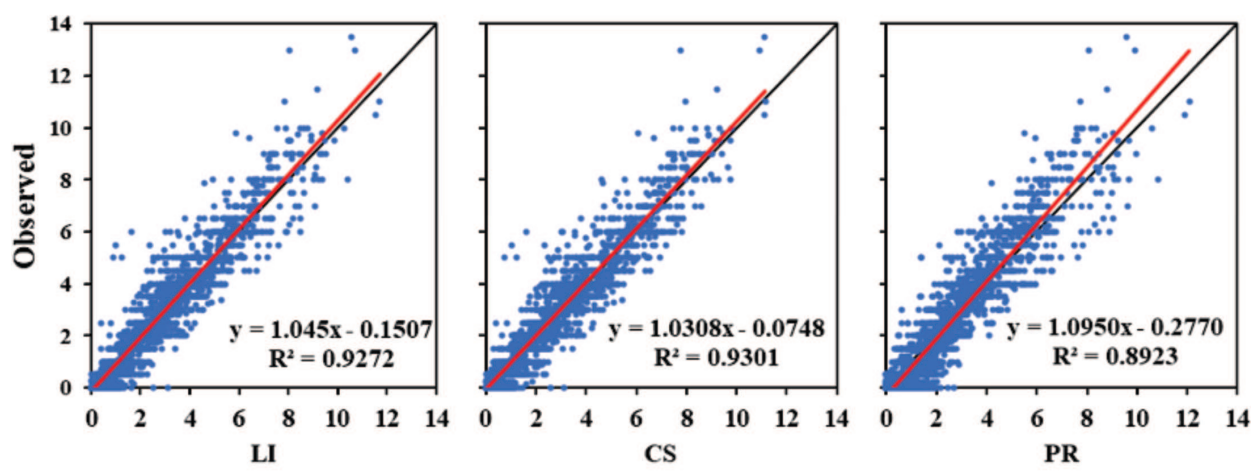

\section{Method}

Figure 5: Scatterplots of observed versus modeled irrigation depths $(\mathrm{mm})$ and the regressed line for the linear interpolation (LI), cubic spline (CS) and second-degree polynomial regression (PR) methods.

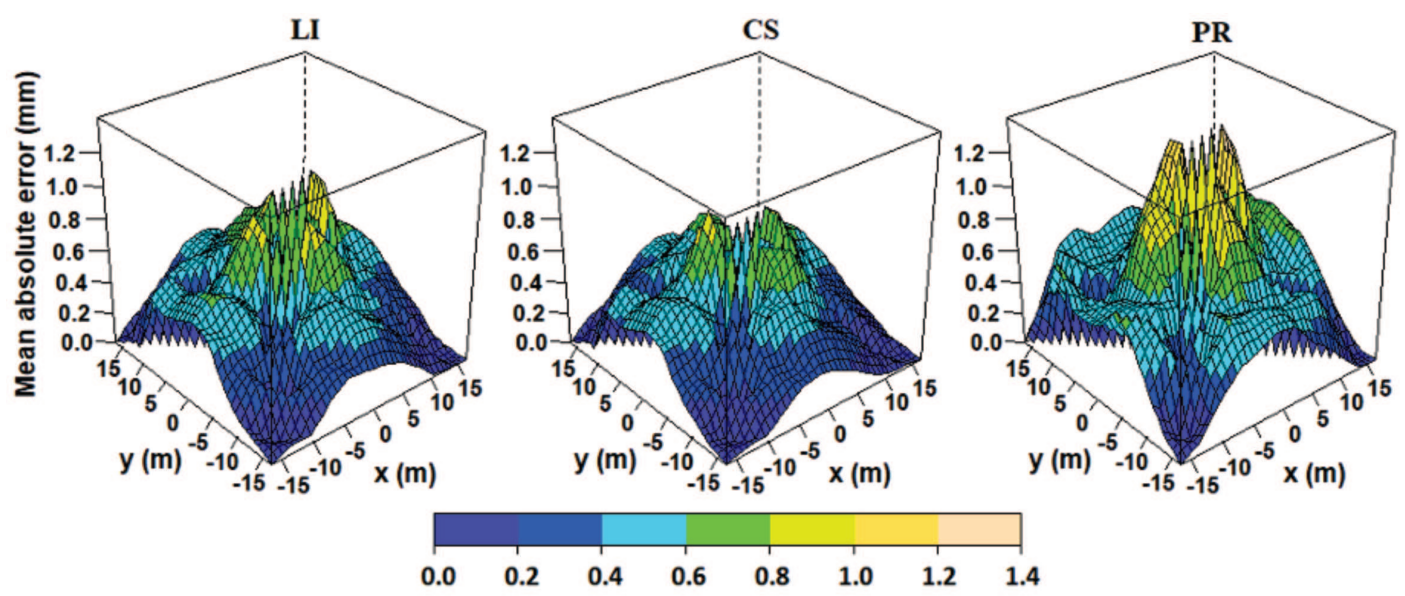

Figure 6: Spatial distribution of the mean absolute error $(\mathrm{mm})$ obtained by applying the linear interpolation (LI), cubic spline (CS) and second-degree polynomial regression (PR) methods. 
distributions were equal to zero and the asymmetries (distortion) are negative. The RE in the 10th percentile were $-31.1 \%,-31.3 \%$ and $-42.2 \%$ for the LI, CS and PR methods, respectively. The calculated 90th percentile values of RE were $35.2 \%, 33.1 \%$ and $49.4 \%$, respectively, for the LI, CS and PR methods.

\section{Additional discussion}

The analysis applied to the general data set agreed with that performed in the results grouped by field tests indicating acceptable performance for the CS and LI methods. The PR method presented a lower performance, as indicated by the distribution of the coefficient of efficiency (Figure 3C), the Wilcoxon-Mann-Whitney test (Figure 3D) and the results shown in the figures 5 to 7. Studying approaches to evaluate the irrigation uniformity of mobile sprinkler machine based on catch-can tests, $\mathrm{Ge}$ et al. (2018) verified the adequacy of the methods cubic spline and degree-six polynomial.

The effect of the wind stands out among the factors that can cause differences in the distribution of irrigation depths obtained with the conventional and the proposed methods. Depending on the speed and on the variation in direction, the wind may cause a significant reduction in uniformity and irrigation efficiency (Darko et al., 2017; Salvatierra-Bellido et al., 2018). It was found that the proposed methods showed a worsening in performance for conditions of low observed CUCs. By analyzing MAE data in comparison with observed CUC for each field test, we found correlation coefficients of $-0.86,-0.83$ and -0.76 for the LI, CS and PR methods, respectively.

Reducing the distances between catch cans located in the diagonals could improve the performance of the proposed methods. The distance used in our field tests may have prevented the recording of significant variations of the irrigation depths, especially in positions close to the sprinkler, as also observed by Zhang et al. (2018). Reducing the distances between catch cans in the diagonals, for instance, to $3 \mathrm{~m}$ (instead of $4.24 \mathrm{~m}$ ), with 1.5 $\mathrm{m}$ between the sprinkler head and the first catch-can

Table 1: Characterization of the probability distributions of the relative error to the means of each test (RE, \%) obtained with the application of the linear interpolation (LI), cubic spline (CS) and second-degree polynomial regression (PR) methods

\begin{tabular}{lrrr}
\hline Statistic & \multicolumn{1}{c}{ LI } & \multicolumn{1}{c}{ C S } & PR \\
\hline Mean (\%) & 3.4 & 1.0 & 4.9 \\
Median (\%) & 4.3 & 1.1 & 5.7 \\
Mode (\%) & 0.0 & 0.0 & 0.0 \\
Standard deviation (\%) & 31.2 & 30.5 & 38.7 \\
Distortion & -1.3 & -1.3 & -0.8 \\
Kurtosis & 10.6 & 11.5 & 5.8 \\
Minimum (\%) & -269.1 & -281.7 & -265.6 \\
Maximum (\%) & 168.4 & 168.4 & 144.9 \\
1st quartile (\%) & -6.9 & -9.4 & -10.8 \\
3rd quartile (\%) & 18.9 & 14.6 & 26.5 \\
\hline
\end{tabular}

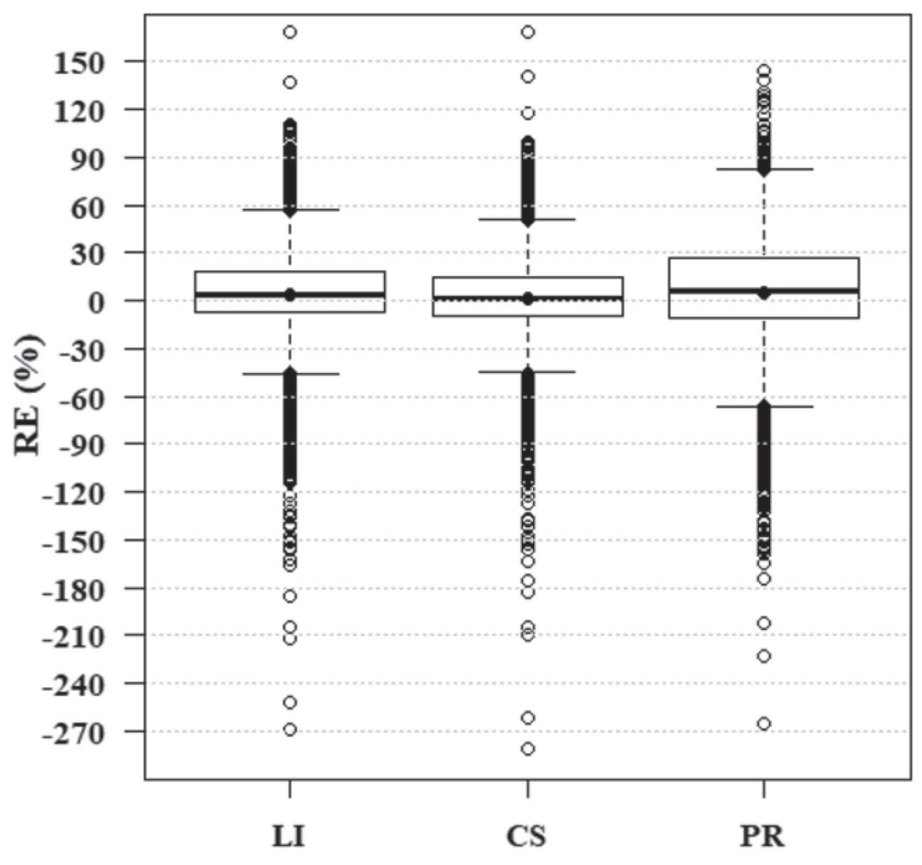

Method

Figure 7: Distribution of the relative error to the means of each test (RE) obtained with the application of the methods of linear interpolation (LI), cubic spline (CS) and second-degree polynomial regression (PR). 
(instead of $2.12 \mathrm{~m}$ ) would allow a better detailing in recording the irrigation depths. In this configuration, 36 catch cans would be required at the four alignments, i.e., $25 \%$ of the number used in the usual methodology. The field test area covered for this configuration would be 12.5\% greater than that considered in Figure 1.

The proposed methodology by applying the LI and CS procedures can be used for simulations of continuous distribution of irrigation depths in irrigated area (densograms) considering the effect of overlaps, even in situations where spacing between sprinklers heads are smaller than the irrigation radius. Thus, larger portions of the irrigated area, in addition to that delimited by sets of four sprinklers heads, could be analyzed using computational modeling applied to studies of uniformity and efficiency of irrigation.

Adaptations in the proposed methodology can be applied to develop additional tools for analysis of uniformity tests for other irrigation methods, such as center pivot and microsprinkler. Procedures for standard testing of the center pivots are described by the Brazilian Association for Technical Standards (ABNT) NBR ISO 11545: 2016 (ABNT, 2016), in which the use of at least two catch-can lines is recommended. The use of two or more lines covering the area can make it possible to record variations in irrigation distribution due to irregularities in topography, variation in wind conditions or instability in the pumping operation. Methods like LI and CS associated to the procedure synthesized in the Equation 1 could be used to model the distribution of irrigation throughout the area.

For the microsprinkler method, procedures usually focus on the flow rate variation (Mazzer et al., 2008). However, the spatial water distribution is relevant in determining the proper positioning of the emitter in relation to plants, especially in the initial development stages of the crops. The methods proposed here can be adapted to generate the distribution of irrigation depths around a microsprinklers.

\section{CONCLUSIONS}

The modelling of the two-dimensional spatial distribution of irrigation depths by using linear and cubic spline interpolation methods, associated with a procedure that uses the angular distance as weighting factor, is suitable for evaluating the water application uniformity.

The fitting method based on second-degree polynomial regression in the configuration studied here performs poorly, not being recommended.

The mean absolute error between the observed and modeled spatial distributions of the irrigation depths is greater for irrigations with lower application uniformity.

\section{ACKNOWLEDGEMENTS, FINANCIAL SUPPORT AND FULL DISCLOSURE}

There was no specific financial support to declare. There was no conflict of interests in carrying the research and the paper is available for full disclosure.

\section{REFERENCES}

ABNT (2016) ABNT NBR ISO 11545:2016 Equipamentos de irrigação agrícola - Máquinas de irrigação pivô central e linear móvel, equipadas com sprayers ou aspersores - Determinação da uniformidade de distribuição de água. Rio de Janeiro, Associação Brasileira de Normas Técnicas. 20p.

Al-Kufaishi SA, Sands JW \& Andersen MN (2009) The impact of various sprinkler irrigation patterns on spatial soil moisture variation in Vertisols. Precision Agriculture, 10:16-33.

ANA (2017) Atlas Irrigação: uso da água na agricultura irrigada. Agência Nacional de Águas. 86p.

ANA (2018) Brazilian water resources report 2017. Agência Nacional de Águas.169p.

Darko RO, Shouqi Y, Junping L, Haofang Y \& Xingye Z (2017) Overview of advances in improving uniformity and water use efficiency of sprinkler irrigation. International Journal of Agricultural and Biological Engineering, 10:1-15.

El-Wahed MA, Sabagh A, Saneoka H, Abdelkhalek AA \& Barutçular C (2015) Sprinkler irrigation uniformity and crop water productivity of barley in arid region. Emirates Journal of Food and Agriculture, 27:770-775.

Fordjour A, Zhu X, Jiang C \& Liu J (2020) Effect of riser height on rotation uniformity and application rate of the dynamic fluidic sprinkler. Irrigation and Drainage, 69:618-632.

Ge MS, Wu PT, Zhu DL \& Zhang L (2018) Application of different curve interpolation and fitting methods in water distribution calculation of mobile sprinkler machine. Biosystems Engineering, 174:316-328.

Gerald CF \& Wheatley PO (2004) Applied numerical analysis. New York, Pearson Addison Wesley. 609p.

Issaka Z, Li H, Jiang Y, Tang P \& Chao C (2019) Comparison of rotation and water distribution uniformity using dispersion devices for impact and rotary sprinklers. Irrigation and Drainage, $68: 881-892$.

Kara T, Ekmekci E \& Apan M (2008) Determining the uniformity coefficient and water distribution characteristics of some sprinklers. Pakistan Journal of Biological Sciences, 11:214219.

Keller J \& Bliesner RD (2000) Sprinkle and trickle irrigation. Caldwell, Blackburn Press. 652p.

Legates DR \& McCabe GJ (1999) Evaluating the use of 'goodnessof-fit' measures in hydrologic and hydroclimatic model validation. Water Resources Research, 35:233-241.

Legates DR \& McCabe GJ (2013) A refined index of model performance: a rejoinder. International Journal of Climatology, 33:1053-1056.

Mann HB \& Whitney DR (1947) On a Test of Whether one of Two Random Variables is Stochastically Larger than the Other. The Annals of Mathematical Statistics, 18:50-60.

Mantovani EC, Villalobos FJ, Organ F \& Fereres E (1995) Modelling the effects of sprinkler irrigation uniformity on crop yield. Agricultural Water Management, 27:243-257. 
Maroufpoor S, Shiri J \& Maroufpoor E (2019) Modeling the sprinkler water distribution uniformity by data-driven methods based on effective variables. Agricultural Water Management, 215:63-73.

Mazzer HR, Pletsch TA, Cruz RL, Vilas Boas MA \& Oliveira EF (2008) Avaliação de desempenho do microaspersor amanco em bancada de testes. Irriga, 13:426-437.

Nascimento AK, Schwartz RC, Lima FA, López-Mata E, Domínguez A, Izquiel A, Tarjuelo JM \& Martínez-Romero A (2019). Effects of irrigation uniformity on yield response and production economics of maize in a semiarid zone. Agricultural Water Management, 211:178-189.

Palisade Corporation (2016) @RISK: Risk analysis and simulation add-in for Microsoft ${ }^{\circledR}$ Excel. Ithaca, Palisade Corporation. $914 \mathrm{p}$.

$\mathrm{R}$ development core team (2019) R: A language and environment for statistical computing. Vienna, R Foundation for Statistica Computing. Available at: https://www.r-project.org/. Accessed on: July $1^{\text {st }}, 2021$

Rezende R, Frizzone JA, Gonçalves ACA \& Freitas PSL (1998) Influência do espaçamento entre aspersores na uniformidade de distribuição de água acima e abaixo da superfície do solo. Revista Brasileira de Engenharia Agrícola e Ambiental, 2:257-261.

Salvatierra-Bellido B, Montero-Martínez J \& Pérez-Urrestarazu L (2018) Development of an automatic test bench to assess sprinkler irrigation uniformity in different wind conditions. Computers and Electronics in Agriculture, 151:31-40.
Simionesei L, Ramos TB, Brito D, Jauch E, Leitão PC, Almeida C \& Neves R (2016) Numerical Simulation of Soil Water Dynamics Under Stationary Sprinkler Irrigation With Mohid-Land. Irrigation and Drainage, 65:98-111.

Wilcoxon F (1945) Individual Comparisons by Ranking Methods. Biometrics Bulletin, 1:80-83.

Willmott CJ, Robeson SM \& Matsuura K (2012) A refined index of model performance. International Journal of Climatology, 32:2088-2094.

Willmott CJ, Robeson SM, Matsuura K \& Ficklin DL (2015) Assessment of three dimensionless measures of model performance. Environmental Modelling and Software, 73:167174.

Yue S \& Wang CY (2002) Power of the Mann-Whitney test for detecting a shift in median or mean of hydro-meteorological data. Stochastic Environmental Research and Risk Assessment, 16:307-323.

Zapata N, Robles O, Playán E, Paniagua P, Romano C, Salvador R \& Montoya F (2018) Low-pressure sprinkler irrigation in maize: Differences in water distribution above and below the crop canopy. Agricultural Water Management, 203:353-365.

Zhang L, Merkley GP, Wu P \& Zhu D (2018) Effect of Catch-Can Spacing on Calculation of Sprinkler Irrigation Application Uniformity. CLEAN - Soil, Air, Water, Wiley - VCH Verlag, 46:1800130. 